\title{
SOSYAL ANKSIYETE VE OTISTIK ÖZELLIKLER
}

Uzm. Klinik Psk. Betül Bilge ÇETINKAYA - Doç. Dr. Elif YÖYEN 


\section{(C) Copyright 2021}

Bu kitabın, basım, yayın ve satış hakları Akademisyen Kitabevi A.Ş.'ne aittir. Anılan kuruluşun izni alnmadan kitabın tümü ya da bölümleri mekanik, elektronik, fotokopi, manyetik kağıt ve/veya başka yöntemlerle çoğaltılamaz, basılamaz, dağıtılamaz. Tablo, şekil ve grafikler izin alınmadan, ticari amaçlı kullanılamaz. Bu kitap T.C. Kültür Bakanlı̆ı bandrolü ile satılmaktadır.

\section{ISBN}

978-625-7401-98-2

\section{Kitap Adı}

Sosyal Anksiyete ve Otistik Özellikler

\section{Yazarlar}

Betül Bilge ÇETINKAYA

ORCID iD: 0000- 0001- 5786- 2646

Elif Güneri YÖYEN

ORCİD iD: 0000-0002-0539-9263

\section{Yayın Koordinatörü \\ Yasin DİLMEN}

Sayfa ve Kapak Tasarımı

Akademisyen Dizgi Ünitesi

\section{Yayıncı Sertifika No}

47518

Baskı ve Cilt

Vadi Matbaacılık

Bisac Code

PSY022020

\section{DOI}

10.37609/akya.126

\section{GENEL DAĞITIM}

\section{Akademisyen Kitabevi A.Ş.}

Halk Sokak 5 / A

Yenişehir / Ankara

Tel: o312 4311633

siparis@akademisyen.com 


\section{YAZARLAR HAKKINDA}

\section{Betül Bilge ÇETINKAYA}

Uzman Psikolog Betül Bilge Çetinkaya, ilkokul ortaokul ve lise öğrenimini doğduğu şehir İzmir'de tamamlamıştır. 2015 yılında İstanbul Aydın Üniversitesi Fen Edebiyat Fakültesi Psikoloji bölümünü ve 2019 y1lında İstanbul Gelişim Üniversitesi Sosyal Bilimler Enstitüsü Psikoloji Anabilim Dalında "Lise öğrencilerinde Sosyal Anksiyete ve Otistik Özellikler İlişkisi“ tezi ile Klinik Psikoloji yüksek lisansını tamamlamıştır.2015- 2016 yıllarında İstanbul PANDOST Panik Atak ve Anksiyete Dostları Derneğinde süpervizyon eşliğinde göreve başlamış, 2016-2017 yıllarında İstanbul Bahçelievler Özel Aile Hastanesinde, 2019 yllında İstanbul Biruni Üniversite Hastanesinde psikolog olarak görev yapmıştır. 2019'dan beri İstanbul Özel Pedamed Psikiyatri Tip Merkezinde klinik psikolog olarak görevine devam etmektedir.

\section{Elif Güneri YÖYEN}

Doçent Doktor Elif Yöyen, 2005 yılında İstanbul Üniversitesi Fen Edebiyat Fakültesi Psikoloji bölümünü ve 2006 yılında aynı üniversitenin Eski Yunan Dili ve Edebiyatı bölümünü bitirdikten sonra, 2008 yllında "Şizofreni ve Bipolar Affektif Bozukluk Hastalarının Rorschach Protokolü Açısından Karşılaştırılması” tezi ile Klinik Psikoloji yüksek lisansını tamamlamıştır. 2012 yılında İstanbul Üniversitesi Adli Tip Enstitüsü Sosyal Bilimler Alanı, Adli ve Klinik Bilimler Alt Alanında "Yatan ve Poliklinikten Takip Edilen 1. Eksen Psikiyatrik Bozukluk Tanısı Almış Kişilerde Şiddet Davranışı ve Eğilimlerinin Karşılaştırılması" konulu tezi ile doktorasını tamamlamıştır. 2005-2014 yılları arasında Eren- 
köy Ruh ve Sinir Hastalıkları Hastanesinde Uzman Klinik Psikolog olarak görev yapan yazar, 2014 yılından beri öğretim üyesi olarak çalışmalarına devam etmektedir. Sakarya Üniversitesi’nde Psikoloji Anabilim Dalı Uygulamalı Psikoloji Bölümünde Doçent Doktor olan yazarın, çok sayıda uluslararası ve ulusal makalesi, kongrelerde sunulmuş bildirileri, kitapları ve kitap bölümleri bulunmaktadır. 


\section{IÇiNDEKILER}

GÍRIŞ 1

\section{BÖLÜM}

ARAŞTIRMANIN ÖZELLiKLERi ..........................................7

1.1. ARAŞTIRMANIN AMACI …………………............................ 7

1.2. ARAŞTIRMANIN PROBLEMİ ................................................. 7

1.2.1. Alt Problem .......................................................................... 7

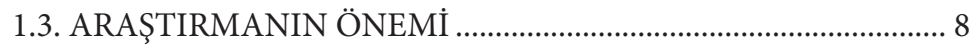

1.4. ARAŞTIRMANIN VARSAYIMLARI.............................................. 9

1.5. ARAŞTIRMANIN SINIRLILIKLARI ………………………........ 9

\section{BÖLÜM}

KURAMSAL ÇERÇEVE............................................................. 11

2.1. SOSYAL ANKSIYETE BOZUKLUĞU........................................... 11

2.1.1. Sosyal Anksiyete Bozukluğu Tanımı ...................................... 11

2.1.2. Sosyal Anksiyete Bozukluğu Tarihçesi ................................... 13

2.1.3. Sosyal Anksiyete Bozukluğu DSM Tanı Ölçütleri ................ 15

2.1.4. Sosyal Anksiyete Bozukluğunun Epidemiyolojisi ................ 18

2.1.5. Sosyal Anksiyete Bozukluğu Eş Tanıları................................. 21

2.1.6. Sosyal Anksiyete Bozukluğu Alt Tipleri................................. 23

2.1.7. Sosyal Anksiyete Bozukluğu Etiyolojisi .................................. 25

2.1.8. Sosyal Anksiyete Ayırıcı Tanılar1 ............................................ 32

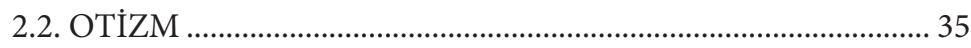

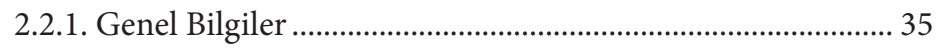

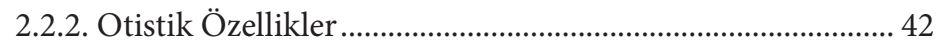

2.2.2.1. Sosyal Etkileşimde Yetersizlik .......................................... 42

2.2.2.2. Dil ve İletişim Becerilerinde Yetersizlik.......................... 46

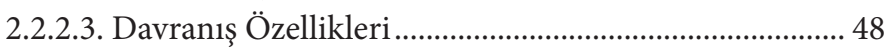

2.2.3. Sağlıklı Bireylerde Otistik Özellikler Görülmesi .................. 50 


\section{BÖLÜM}

ARAŞTIRMANIN YÖNTEMİ

3.1. ARAŞTIRMADA KULLANILAN VERI

TOPLAMA ARAÇLARI 54

3.1.1. Kişisel Bilgi Formu (EK-A)...................................................... 54

3.1.2. Ergenler İçin Sosyal Anksiyete Ölçeği (ESAÖ) (EK-B) 54

3.1.3. Sosyal Karşıllıklılık Ölçeği (SKÖ)

(Social Responsiveness Scale -SRS)(EK-C).................................... 56

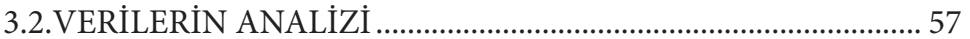

\section{BÖLÜM}

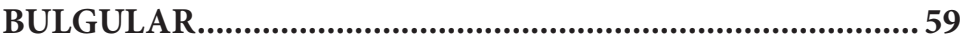

4.1. Çalışmanın Demografik Özellikleri.................................................. 59

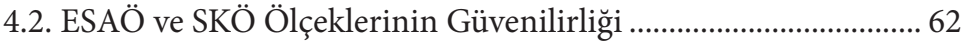

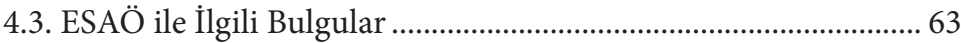

4.3.1. Demografik Özelliklere Göre Yüksek-ESAÖ ve Düşük-

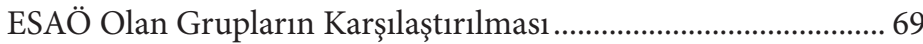

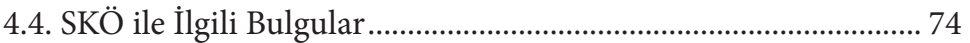

4.5. ESAÖ ve SKÖ'nün Birlikte Değerlendirilmesine

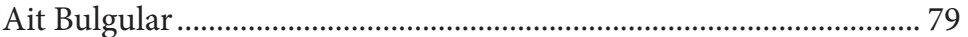

4.5.1. Korelasyon Bulgular1 ........................................................... 82

\section{BÖLÜM}

TARTIŞMA VE SONUÇ

5.1. Sosyal Anksiyete Düzeylerine Göre Sosyodemografik

Özelliklerin Tartışılması

5.2. Otistik Özelliklere Göre Sosyodemografik Özelliklerin

Tartışılması....

5.3. Sosyal Anksiyete ile Otistik Özellikler

İlişkisinin Tartışılması. 


\section{KISALTMALAR}

AGE: Adı Geçen Eser

ÇKB: Çekingen Kişilik Bozukluğu

DSM: Diagnostic and Statistical Manual of Mental

Disorders

ECA: Epidemiyologic Catchment Area

ESAÖ: Ergenler İçin Sosyal Kaygi Ölçeği

OSB: Otizm Spektrum Bozukluğu

SAB: Sosyal Anksiyete Bozukluğu

SKÖ: $\quad$ Sosyal Karşılıklılık Ölçeği

SPSS: $\quad$ Statistical Package for the Social Sciences 


\section{KAYNAKLAR}

\section{KİTAPLAR}

Amerikan Psikiyatri Birliği, Mental Bozuklukların Tanısal ve Sayımsal Elkitabı (DSM-IV), Çev. Ertuğrul Köroğlu, Hekimler Yayın Birliği, Ankara, 1994.

American Psychiatric Association. 1994. Diagnostic and statistical manual of mental disorders, 4th edition. Washington, DC: American Psychiatric Association

Amerikan Psikiyatri Birliği, Ruhsal Bozuklukların Tanısal ve Sayımsal Elkitabı, (DSM-V), çev. Köroğlu E. Hekimler Yayın Birliği, Ankara, 2013.

APA, American Psychiatric Association (2013). Diagnostic and statistical manual of mental disorders (5th ed.). Washington, DC

American Psychiatric Association, Diagnostic and statistical manual of mental disorders Washington, DC: Author, 2000 s. 239.

BECK Aaron T., EMERY Gary, Anksiyete Bozuklukları ve Fobiler, Çev. Veysel Öztürk, Litera Yayınevi, İstanbul, 2015.

BURGER Jerry M., Kişilik, Çev. İnan Deniz Ergüvan Sarığlu, Kaknüs Yayınları, İstanbul, 2006.

BUTCHER James N., MINNEKA Susan, HOOLEY Jill M., Anormal Psikoloji, Çev. Okhan Gündüz, Kaknüs Yayınları, İstanbul, 2013. BÜYÜKÖZTÜRK Şener,Sosyal Bilimler İçin Veri Analizi El Kitabı. Pegem Akademi Yayınları,Ankara, 2010.

CERVONE Daniel ve PERVIN Lawrence A., Kişilik Psikolojisi, Çev. Mustafa Baloğlu, Nobel Akademi, Ankara, 2016. 
CROZIER W. Ray and ALDEN Lynn E., The Essential Handbook of Social Anxiety for Clinicians, West Sussex John Wiley\&Sons, England, 2005.

DİNÇMEN Kriton, Deskriptiv ve Dinamik Psikiyatri, Sağol Matbaası, İstanbul, 1969.

EKŞİ Aysel, Ben Hasta Değilim: Çocuk Sağlığı ve Hastalıklarının Psikososyal Yönü, Nobel Tip Kitapevi, İstanbul, 1999.

GHAZIUDDIN Mohammad, Mental Health Aspects of Autism and Asperger Syndrome, Jessica Kingsley Publishers,2005.

GENÇTAN Engin, Psikanaliz ve sonrası, Remzi kitapevi, İstanbul, 2000.

KAPLAN Harold I. ve SADOCK Benjamin J., Klinik Psikiyatri, Çev. Ercan Abay, Nobel Tip Kitabevleri, 2014.

KORKMAZ Barış, Asperger Sendromu, Adam Yayınları, İstanbul, 2003.

KORKMAZ Barış, Yağmur Çocuklar, Doğan Kitapçılık, İstanbul, 2000.

KOYUNCU Ahmet, İkincil Sosyal Fobiler, Roza Yayınevi, İstanbul., 2016.

LEAHY Robert L., Bilişsel Terapi ve Uygulamaları, Çev. T. Özakkaş, Litera Yayınc1lik, İstanbul, 2007.

MUKEDDES Nahit Motovalli, "Otizm Spektrum Bozuklukları Tanı ve Takip”, Nobel Tip Kitabevleri, 2017, İstanbul.

ÖZTÜRK M. Orhan ve ULUŞAHIN Aylin, Ruh Sağlı̆g ve Bozuklukları, 1. Cilt, Nobel Tip Kitabevi, Ankara, 2014.

REINECKE Mark A, DATTILLIO Frank M., FREEMAN Arthur,,Çocuklar ve Ergenlerle Bilişsel Terapi, Çev. Yavuz Selim Altındal, Litera Yayıncilık, İstanbul, 2017.

STEIN Dan J., HOLLENDER Eric, ROTHBAUM Barbara O., Textbook of Anxiety Disorder, Second edition. Washington D.C., American Psychiatric Publishing, 2009.

VOLKMAR Fred R., ROGERS Sally J., PAUL Rhea, PELPHREY Kevin A., Handbook of Autism and Pervasive Developmental Disorders, Volume 1: Diagnosis, Development, Neurobiology, and Behavior, 4rd Edition, John Wiley \& Sons,2014.

\section{MAKALELER}

AYDIN Arzu ve TEKİNSAV SÜTÇÜ Serap, "Ergenler için sosyal kaygı ölçeğinin (ESKÖ) geçerlik ve güvenirliğinin incelenmesi." Çocuk ve Gençlik Ruh Sağlı̆̆ı Dergisi, 2007,14(2), 79-89 
AYDIN Aydan ve SARAÇ Tuğba, "Otistik Çocuk Ebeveynlerinin Geniş Otizm Fenotipi ve Aleksitimi Özellikleri Arasındaki İlişki”, Dumlupınar Üniversitesi Sosyal Bilimler Dergisi ,2014; 41: 297308.

BAL Ufuk, ÇAKMAK Soner, UĞUZ Şükrü, "Anksiyete Bozukluklarında Cinsiyete Göre Semptom Farklılıkları”, Arşiv Kaynak Tarama Dergisi, 2003, 22(4):441-459.

BEIDEL Deborah. C.,'Social anxiety disorder: Etiology and early clinical presentation." The Journal of Clinical Psychiatry, 1998, 59(17), 27-32.

BEJEROT Susanne., ERIKSSON Jonna M., MÖRTBERG Ewa., "Social anxiety in adult autism spectrum disorder." Psychiatry Research,2014; 220(1-2), 705-707.

BODUR Şahin ve SOYSAL A.Şebnem,, "Otizmin Erken Tanısı ve Önemi", Sürekli Tip Eğitimi Dergisi, 2004, 13(10); 394-398.

CATCH DC, RAN N, SMIT JH, VAN Balkom AJ, COMIJS HC.” Symptom overlap between autism spectrum disorder, generalized social anxiety disorder and obsessive-compulsive disorder in adults: A preliminary case-controlled study." Psychopathology. 2007;41(2):101-110.

CONSTANTINO John N., DAVIS Sandra A,TODD Richard D.,SCHINDLER Matthew K.,GROSS Maggie M.,BROPHY Susan L.,METZGER Lisa M.,SHOUSHTARI Christiana S.,SPLINTER Reagan and REICH Wendy, "Validation of a Brief Quantitative Measure of Autistic Traits: Comparison of the Social Responsiveness Scale With the Autism Diagnostic İnterview-Revised.", Journal of Autism and Developmental Disorders ,2003, 33: 427-33.

DALRYMPLE Kristy L. "Issues and controversies surrounding the diagnosis and treatment of social anxiety disorder", Expert Review of Neurotherapeutics, 2012,12 (8):993-1008.

DOĞANGÜN Burak, "Özel Eğitim Gerektiren Psikiyatrik Durumlar", İ.Ü. Cerrahpaşa Tip Fakültesi Sürekli Tip Eğitimi Etkinlikleri Sempozyumu, Mart 2008, Say1: 62, İstanbul, 157-174.

DİLBAZ Nesrin, "Sosyal Anksiyete Bozukluğu: Tanı, Epidemiyoloji, Etiyoloji, Klinik ve Ayırıcı Tanı", Klinik Psikiyatri, 2000, 2, 3-21.

DİLBAZ Nesrin, "Sosyal Fobi”, Psikiyatri Dünyası, 1997, 1, 18-24

DİLBAZ Nesrin ve GÜZ Hatice, "Sosyal Kaygı Bozukluğunda Cinsiyet Farklılıkları”, Nöropsikiyatri Arşivi, 2002, 39(2-3-4): 79-86. 
ELLIS Albert, "Rational-emotive treatment of simple phobias. Psychotherapy: Theory, Research, Practice, Training", 1991. 28(3), 452-456.

ER SABUNCUOĞLU Dudu Melek, “Otizm Bilgi Düzeyi: Okul Öncesi Eğitimcileri”, Hacettepe Üniversitesi Sağlık Bilimleri Fakültesi Dergisi, 2016, 3(1):28-52,s.30.

ERIKKSSON Jonna M., BEJEROT Sussanne, MORTBERG Ewa," Social anxiety in adult autism spectrum disorder", Psychiatry Research, 2014, Volume 220, p.705-707.

EVREN Cüneyt, "Sosyal Anksiyete Bozukluğu ve Alkol Kullanım Bozuklukları",Psikiyatride Güncel Yaklaşımlar, 2010;2(4):472-515.

FAKHORY Marc, "Autistic spectrum disorders: A review of clinical features, theories and diagnosis". International Journal of Developmental Neuroscience, 2015; 43: 70-77.

FARAVELLI C, ZUCCHI C., VIVIANI B, Salmoria, PERONE A., PAIONNI A.,et al.," Epidemiology of social phobia:A clinical approach", Eur Psychiatry 2000; 15(1): 17-24.

FREETH M,, BULLOCK T., MILNE E., "The distribution of and relationship between autistic traits and social anxiety in a UK student population".Autism. 2012, Sep;17(5):571-81.

GRANT Bridget, HASIN D.S., BLANCO C., STINSON F.S., CHOU S.P., GOLDSTEIN R.B., DAWSON D.A., SMITH S, SAHA T.D, HUANG B., "The epidemiology of social anxiety disorder in the United States: results from the National Epidemiologic Survey on Alcohol and Related Conditions.", The Journal of Clinical Psychiatry, 2005; 66:1351-1161.

GÜZ Hatice ve DİLBAZ Nesrin, "Sosyal Kaygı Bozukluğu ile Panik Bozukluğu Olgularının Demografik ve Bazı Klinik Özellikler Açısından Karşılaştırılması", Klinik Psikiyatri, 2003, 6:32-38.

HUNDSON Jennifer L.and RAPEE Ronald M., "The Origins of Social Phobia", Behav Modif, 2000, Cilt:24, Say1:1, 102-29.

JOBE Lisa E. and WHITE Susan Williams, "Loneliness, Social Relationships, and a Broader Autism Phenotype in College Students", Personality and Individual Differences, 2007, $42 ; 1479-1489$.

KADAK Muhammet Tayyip, DEMİR Türkay, DOĞANGÜN Burak, "Otizmde Yüz ve Duygusal Yüz İfadelerini Tanıma", Psikiyatride Güncel Yaklașımlar, 2013, 5(1):15-29.

KARAMUSTAFAOĞLU Oğuz ve YUMRUKÇAL Hüseyin, "Depresyon ve Anksiyete Bozuklukları", Şişli Etfal Hastanesi Tip Bülteni, 2011,45(2), 65-74 
KAVAL Nesibe Olgun ve TEKİNSAY SÜTÇÜ Serap, "Çocuk ve Ergenlerde Sosyal Anksiyete Bozukluğunun Tedavisinde Bilişsel Davranış̧̧1 Grup Terapisinin Etkililiği: Sistematik Bir Gözden Geçirme”, Psikiyatride Güncel Yaklaşımlar, 2016;8(1):3-22.

KESSLER Ronald C., CHIU Wai Tat, DEMLER Olga, MERIKANGAS KR, WALTERS EE. "Prevalence, severity, and comorbidity of 12-month DSM-IV disorders in the National Comorbidity Survey Replication". Arch Gen Psychiatry. 2005; 62:617-27.

KESSLER Ronald C, MCGONAGLE Katherine A, ZHAO Shanyang, NELSON CB, HUGHES M, Eshleman S.et al. "Lifetime and 12month prevalence of DSM-III-R psychiatric disorders in the United States: results from the National Comorbidity Survey. Arch", Gen Psychiatry, 1994; 51:8-19

KOLAT Uğur, KOLAT Esra, ÇELİK ERDEN Selime, UZUN Uğraş Erman, ÖNEM AKÇAYAKA Rabia ve SEVİNDİK Can Sait, "Sosyal Anksiyete Bozukluğu Hastalarının Mizaç ve Karakter Özellikleri”, Anadolu Psikiyatri Dergisi , 2015, 16, 122-129

KORKMAZ Barış, " Otizm: Klinik ve nörobiyolojik özellikleri, erken tanı, tedavi ve bazı güncel gelişmeler”, Türk Pediatri Arşivi Dergisi, 2010,45:80. Yil:37-44.

KÜÇÜK Önder, ULAŞ Gözde, YAYLACI Ferhat, MİRAL Süha, "Geniş Otizm Fenotipi", Psikiyatride Güncel Yaklaşımlar, 2018;10(2):218-238.

LA GRECA Annette and STONE Wendy L., "Social anxiety scale for children-revised, Factor structure and concurrent validity", Journal of Clinical Child Psychology, 1993,22(1), s.17-27.

LA GRECA Anette, DANDES Susan Kraslow, WICK Patricia, SHAW Kimberly and Stone Wendy L., "Development of the Social Anxiety Scale for Children, Reliability and concurrent validity", Journal of Clinical Child Psychology, 1988,17(1), s.84-91.

LEARY Mark R. And KOWALSKI Robin M.,. "The self-presentation model of social phobia" Ed. Richard G. Heimberg Social phobia: Diagnosis, Assessment, and Treatment.Guilford Press, New York, 1995, 94-112.

LECRIBIER Yves and WEILLER Emmaneulle, "Comorbidities in social phobia." International Clinical Psychopharmacology; 1997; 12(6):17-21.

LEVINSON Cheri A., RODEBAUGH Thomas L., WHITE Emily K., MENATTI Andrew, WEEKS Justin W., LACOVINO Juliette M. 
and WARREN Cortney S., " Social appearance anxiety, perfectionism, and fear of negative evaluation: distinct or shared risk factors for social anxiety and eating disorders?", Appetite, 2013, ;67:125-33.

LIEBOWITZ M.R., "Update on the diagnosis and treatment of social anxiety disorder." The Journal of Clinical Psychiatry. 1999;60 Suppl 18:22-6.

LIEW Shi Min,THEVARAJA Nishta, HONG Ryan Y., MAGIATI Iliana, "The relationship between autistic traits and social anxiety, worry, obsessive-compulsive, and depressive symptoms: specific and non-specific mediators in a student sample." J Autism Dev Disord., 2015;45(3):858-72.

LIPSITZ Joshua D. and SCHNEIER Franklin R., "Social phobia. Epidemiology and cost of illness." Pharmacoeconomics, 2000; 18(1):23-32.

LORD Catherine, SHULMAN Chory, DILAVORE Pamela."Regression and word loss in autistic spectrum disorders".Journal of Child Psychol and Psychiatry,2004;45(5):936-55

MANSELL W., CLARK DM., "How do I appear to others? Social anxiety and processing of the observable self.", Behaviour Research and Therapy, 1999 37(3), 419-434.

MUZINA David J. and EL-SAYEGH Samar, "Recognizing and treating social anxiety disorder". Cleveland Clinic Journal of Medicine, 2001; 68:649-657.

NICHOLAS J.S., CHARLES J.M., CARPENTER L.A., KING L.B., JENNER W., SPRATT E.G., "Prevalence and characteristics of children with autism-spectrum disorders., Ann Epidemiol, 2008;18(2):130-6.

NOYAN Handan ve SERTEL BERK N. Özlem, "Ergenlere Sosyal Fobi, İçe Ve Dışa Dönük Kişilik Özellikleri Ve Okul Başarı Durumu" İstanbul Üniversitesi Psikoloji Çalışmaları Dergisi, 2007, Cilt 27, $31-50$.

OLIVERAS R. Jose,GARCIA-LOPEZ Luisjoaquin, HIDALGO M.Dolores, LA GRECA Anette, "A pilot study on normative data for two social anxiety measures: The Social Phobia and Anxiety Inventory and the Social Anxiety Scale for Adolescents", International Journal of Clinical and Health Psychology,2002, 2(3), s.467-476.

ÖNGIDEN Nilgün ve BAYKARA Burak, "Anksiyete Tanısı Almış Çocuklar Üzerinde Bilişsel Davranış̧̧ı Grup Terapisinin Etkililiği”, 
Bilişsel Davranış̧̧ı Psikoterapi ve Araştırmalar Dergisi, 2015, Cilt: 1, 26-37.

ÖZEREN Gül Sultan,"Otizm Spektrum Bozukluğu (OSB) ve Hastalığa Kanıt Penceresinden Bakış", Acıbadem Üniversitesi Sağlık Bilimleri Dergisi, 2013, 4(2):57-63.

ÖZDİKMENLİ DEMİR Gözde, "Sosyal Fobinin Etiyolojisinin İncelenmesi Amacıyla Gerçekleştirilen Araştırmalara Genel Bir Bakış", Akademik İncelemeler Dergisi, 2009.

ÖZTÜRK Abdülkadir, "Sosyal Kaygıyı Açılklayan Yaklaşımlar", Elektronik Sosyal Bilimler Dergisi, 2014, Cilt:13, Say1:48, 15-26.

PULEO Connor M, and KENDALL Philip C., "Anxiety disorders in typically developing youth: Autism spectrum symptoms as a predictor of cognitive-behavioral treatment." Journal of Autism and Developmental Disorders. 2011;41(3):275-286.

PIVEN Joseph,PALMER Pat, JACOBİ Dinah, CHILDRESS Debra and ARNDT Stephan, "Broader autism phenotype: evidence from a family history study of multiple-incidence autism families.", Am J Psychiatry, 1997; 154:185-190.

RUTTER Michael and SCHOPLER Eric, "Classification of pervasive developmental disorders: some concepts and practical considerations." J Autism Dev Disord, 1993;22(4):459-82.

SARAÇ Tuğba ve AYDIN Aydan., "Otistik Bireylerin Özellikleri ile Ebeveynlerinin Geniş Otizm Fenotipi ve Aleksitimik Özelliklerinin İncelenmesi.", International Journal of Social Science, 2014, 24;183-209.

SAYAR Kemal, SOLMAZ Mustafa, ÖZTÜRK Mücahit, ÖZER Akil, ARIKAN Meltem.,"Yaygın Sosyal Fobi Hastalarında Çekingen Kişilik Bozukluğu ve Psikopatolojiye Etkileri”, Klinik Psikiyatri Dergisi, 2000, Cilt:3, 163-169.

SCHREIER A., WITTCHEN H.U., HÖFLER M., LİEB R., "Anxiety disorders in mothers and their children: prospective longitudinal community study", The British Journal of Psychiatry, 2008, Cilt: 192, 308-309.

SEVINCÇOK Levent, DEREBOY Ferhan, DEREBOY Çiğdem, "Çekingen Kişilik Bozukluğunun Klinik Özellikleri ve Tedavisi”,Klinik Psikiyatri, 1998;1:22-26.

SIMONOFF E, PICKLES A, CHARMAN T, CHANDLER T, BAIRD G. "Psychiatric disorders in children with autism spectrum disorders: prevalence, comorbidity, and associated factors in a popula- 
tion-derived sample." Journal of the American Academy of Child \& Adolescent Psychiatry. 2008;47(8):921-929.

STEIN Murray B., STEIN Dan J., "Social anxiety disorder" The Lancet, 2008, 371, 1115-1125.

STEIN Murray B., TORGRUD Laine J., WALKER John R.,'Social Phobia Symptoms, Subtypes, and Severity:Findings From a Community Survey", Archives of General Psychiatry,2000, 57(11), 10461052.

STEIN MB, WALKER JR, FORDE DR., "Setting diagnostic thresholds for social phobia: Considerations from a community survey of social anxiety." Am J Psychhiatry, 1994; 151 :408-12.

STINSON Frederick S., DAWSON Deborah A., CHOU S, Patricia, SMITH Sharon, GOLDSTEIN Rise B., RUAN W. June and GRANT Bridget F., "'The epidemiology of DSM-IV specific phobia in the USA, results from the National Epidemiology Survey on Alcohol and Related Conditions," Psychological Medicine, 2007, 37(7):1047-1059.

SOUTH Mikle,LARSON Michael J.,WHITE Sarah E., DANA Julianne, CROWLEY Michael J., "Better fear conditioning is associated with reduced symptom severity in autism spectrum disorders.", Autism Research. 2011;4(6):412-421.

SUNGUR Mehmet Z., "Bilişsel-Davranışçı Yaklaşımlar ve Sosyal Fobi", Klinik Psikiyatri Dergisi,2000,Ek 2:27-32.

SUNGUR Mehmet Z., "Fobik Bozukluklar", Psikiyatri Dünyası, 1997 Cilt:1, 5-11.

ŞAR Vedat , ” DSM-5 Taslak Tanı Ölçütlerine Genel bir Bakış: «Batı Cephesinde Yeni bir şey Yok mu?” ,Klinik Psikiyatri Dergisi, 2010, Cilt:13, 196-208.

TONGE Natasha A., RODEBAUGH Thomas L., FERNANDEZ Katya C., LIM Michelle H., "Self-reported social skills impairment explains elevated autistic traits in individuals with generalized social anxiety disorder.” J Anxiety Disord. 2016 ;38:31-6.

TORAMIŞ ÖZKAYA Banu, "Yaygın Gelişimsel Bozukluklardan Otizm Spektrum Bozukluğuna Geçiş: DSM-5’te Karşımıza Çıkacak Değişiklikler", Psikiyatride Güncel Yaklaşımlar, 2013;5(2):127-139.

TÖRET Gökhan ve ÖZMEN E. Rüya, "Erken Çocukluk Döneminde Otizm Spektrum Bozukluğu Olan Çocuklarda Taklit Becerileri", Özel Eğitim Dergisi, 2014, 15(3) 51-66. 
TURAN Metin, ÇİLLİ Ali S., AŞKIN Rüstem, HERKEN Hasan, KAYA Nazmiye, KUCUR Rahim, "Sosyal Fobinin Diğer Psikiyatrik Hatalıklarla Birlikteliği”, Klinik Psikiyatri, 2000, Cilt:3, 170-175.

TURK CL, HEIMBERG RG, ORSILLO SM, HOLT CS, GITOW A, STREET LL, SCHNEIER FR, LIEBOWITZ MR.”, An investigation of gender differences in social phobia. "J Anxiety Disord. 1998; 12:209-23

TÜKEL Raşit, "Panik Bozukluğu", Klinik Psikiyatri, 2002, Cilt:3, 5-13.

TÜRKÇAPAR Hakan, "Sosyal Fobinin Psikolojik Kuramı", Klinik Psikiyatri, 1999, Cilt:2, 247-253.

ÜNAL Selin, GÜLER Ayşegül Selcen,DEDEOĞLU Ceyda, TAŞKIN Beril, YAZGAN Yankı, "Dikkat Eksikliği Hiperaktivite Bozukluğu tanısı olan klinik örneklemde sosyal karşıllklılık: Okul örnekleminden elde edilen kontrol grubu ile karşılaştırma", 19. Ulusal Çocuk ve Ergen Ruh Sağlığı ve Hastalıkları Kongresi,2009.

VERTUE Frances M., "From Adaptive Emotion to Dysfunction: An Attachment Perspective on Social Anxiety Disorder", Personality and Social Psychology Review, 2013,7(2), 170-191.

VOLKMAR Fred R., LORD Catherine, BAILEY Anthony, SCHULTZ Robert T.and KLIN Ami., "Autism and pervasive developmental disorders", Journal of Child Psychology and Psychiatry 2004,45(1);135-170.

WHITE Susan W., OLLENDICK Thomas H. and BRAY Bethany C.., "College students on the autism spectrum: Prevalence and associated problems." Autism, 2011;15:683-671.

WITTCHEN H.U. and FEHM L., "Epidemiology and natural course of social fears and social phobia., Acta Psychiatrica Scandinavica, 2003;108(417):4-18.

WITTCHEN H.U.,FUETSCH M.,SONNTAG H. MULLER N.,LIEBOWITZ M., "Disability and quality of life in pure and comorbid social phobia. Findings from a controlled study." European Psychiatry 1999; 14(3):118-131.

YALÇIN Melikenaz ve TEKINSSAY SÜTÇÜ Serap, "Yetişkinlerde Sosyal Fobinin Tedavisinde Bilişsel Davranış̧̧ı Grup Terapisinin Etkililiği: Sistematik Bir Gözden Geçirme", Psikiyatride Güncel Yaklaşımlar, 2016, 8(1), 61-78.

YOSUNKAYA Elif, "Otizm Etiyolojisinde Genetik ve Güncel Perspektif” İstanbul Tıp Fakültesi Dergisi ,2013,76(4);84-88. 


\section{TEZLER}

AYDINOĞLU Ünsal, Eşikaltı Otistik Belirtilerin Yaygınlığı, Zihin Kuramına Etkisi ve Psikiyatrik Bozuklarla Komorbiditesi, Atatürk Üniversitesi, Tip Fakültesi, Erzurum, 2015, Yayımlanmamış Uzmanlık Tezi

AYKAN ZERGEROĞLU Simge, Otistik Özellik Gösteren Sağlıklı Bireylerde Mizah Algısının ve EEG Konnektivitesinin İncelenmesi, Sağlık Bilimleri Enstitüsü, Ankara Üniversitesi, Ankara, 2018, Yayımlanmış Doktora Tezi.

BALTACI Önder, Üniversite Öğrencilerinin Sosyal Kaygı, Sosyal Destek ve Problem Çözme Yaklaşımları Arasındaki İlişkinin İncelenmesi, Eğitim Bilimleri Enstitüsü, Selçuk Üniversitesi, Konya, 2010. Yayımlanmamış Yüksek Lisans Tezi

BAYRAKTUTAN Mustafa, Sosyal Anksiyete Bozukluğu Olan Hastalarda Empati Becerisi, Aleksitimi, Depresyon, Anksiyete Düzeyleri İle Sempatik Deri Yanıtı İlişkisi Ve Tibbi Tedavinin Etkileri, Tip Fakültesi Psikiyatri Anabilim Dalı, Pamukkale Üniversitesi, Denizli, 2014, Yayımlanmamış Uzmanlık Tezi.

CELAYİR Fatih Mehmet, Otizm Bulgusu Gösteren Bireylerdeki Genetik Değişikliklerin MLPA Yöntemi ile Ortaya Konması, Eskişehir Osmangazi Üniversitesi,Tip Fakültesi,Eskişehir,2012,s.5. Yayımlanmamış Uzmanlık Tezi

DAĞAŞAN Gökçe, Sağlıklı Erişkin Üniversite Öğrencilerinde Dikkat Eksikliği Hiperaktivite Bozukluğu İle Sosyal Anksiyete Bozukluğu Arasındaki İlişki, Sosyal Bilimler Enstitüsü, Üsküdar Üniversitesi, İstanbul, 2017.Yayımlanmamış Yüksek Lisans Tezi.

DİKMEN Ufuk, Otistik Davranış Kontrol Listesi ve Değiştirilmiş Erken Çocukluk Dönemi Otizm Tarama Ölçeği’nin Otistik Çocukları Belirleme Yönünden Karşılaştırılması,Eğitim Bilimleri Enstitüsü, Marmara Üniversitesi, İstanbul, 2010.

DOĞAN Tayfun, Bilişsel ve Kendini Değerlendirme Süreçlerinin Sosyal Anksiyete Açısından İncelenmesi, Sosyal Bilimler Enstitüsü, Sakarya Üniversitesi, Sakarya, 2009, Yayımlanmıș Doktora Tezi.

ELDOĞAN Dilay, Sosyal Anksiyete Bozukluğu Belirti Düzeyi Yüksek ve Düşük Olan Bireylerin Çeşitli Psikolojik Değişkenler ve Bilişsel Yanlılıklar Açısından Karşılaştırılması:Bir Bilgece Farkındalık Temelli Psikoeğitim Programı Önerisi, Sosyal Bilimler Enstitüsü, Hacettepe Üniversitesi, Ankara, 2017. Yayımlanmış Doktora Tezi 
ÖZÇELIKK Celal Onun, Üniversite Öğrencilerinde Sosyal Fobi ve İnternet Bağımlılı̆̆ 1 Arasındaki İlişkinin İncelenmesi, Sosyal Bilimler Enstitüsü, Üsküdar Üniversitesi, İstanbul, 2016, Yayımlanmış Yüksek Lisans Tezi.

PARÇAL Kübra Fadime, Ergenlerin Sosyal Anksiyete Düzeyleri İle Özgüven Algıları Arasındaki İlişkinin İncelenmesi, Sosyal Bilimler Enstitüsü, Haliç Üniversitesi, İstanbul, 2018, Yayımlanmamış Yüksek Lisans Tezi.

SAPMAZ Fatma ,Bilişsel Davranışçı Yaklaşıma Dayalı Grupla Psikoloji Danışmanı Sosyal Anksiyete,Reddedilme Duyarlılığı ve Kişilerarası Duyarlılık Üzerine Etkisi, Eğitim Bilimleri Enstitüsü, Sakarya Üniversitesi, Sakarya, 2011.Yayımlanmış Doktora Tezi.

ULUYOL Mustafa, Çocukların Otizm spektrum Bozukluğu Derecesi İle Duyu-Biliş- Motor Özellikleri Arasındaki ilişkilerin Belirlenmesi, Eğitim Bilimleri Enstitüsü, Anadolu Üniversitesi, Eskişehir, 2015.

UĞURLU Mert, Sosyal Anksiyete Bozukluğu Olan Hastalarda Öfke Düzeyinin Komorbidite ve İşlevsellik Üzerine Etkisi, Tip Fakültesi, Ankara Üniversitesi, Ankara, 2009.

YAĞIZ Ayşegül, Üniversite Öğrencilerinde Sosyal Anksiyete Bozukluğu Yaygınlığı, Bu Bozuklukta Öfke İfade Tarzı, Beden Self İlişkisi ve Yeme Tutumlarının Değerlendirilmesi, Tip Fakültesi, Cumhuriyet Üniversitesi, Sivas, 2014, Yayımlanmış Uzmanlık Tezi.

\section{INTERNET KAYNAKLARI}

T.C. Aile ve Sosyal Politikalar Bakanlığı Engelli ve Yaşlı Hizmetleri Genel Müdürlüğü “Otizm Spektrum Bozuklukları”, https://eyh.aile. gov.tr/otizm-spektrum-bozuklugu-kitabi-2016

Tohum Otizm Vakfı, “Türkiyede Otizm Spektrum Bozukluğu ve Özel Eğitim”, İstanbul,2017,s.10.https://www.tohumotizm.org.tr/ wpcontent/uploads/2018/10/tosboe2017.pdf 